\title{
Mitral annular peak systolic velocity in pediatric patients with ectopic atrial tachycardia
}

\author{
Martin Koestenberger $^{1} \cdot$ William Ravekes ${ }^{2}$
}

Received: 17 April 2015 /Accepted: 27 April 2015 /Published online: 5 May 2015

(C) Springer-Verlag Berlin Heidelberg 2015

To the Editor,

We read with great interest the article "Optimal noninvasive assessment of initial left ventricular dysfunction in children with ectopic atrial tachycardia" from Ge et al. [1]. The authors found that left ventricular (LV) function assessed with tissue Doppler imaging (TDI) parameters such as the mitral annular peak systolic velocity (Sm) improves an early detection of LV dysfunction in children with ectopic atrial tachycardia (EAT) [1]. In our opinion, this is an excellent statement describing the current needs for simple alternative measurements compared to the conventionally used LV ejection fraction (LVEF). Ge et al. [1] investigated children with an age range of 0.1-14.7 years and found, besides reduced Sm values in patients with elevated NT-proBNP levels, that Sm positively correlated with increasing age. They stated that their findings are in contrast to a study from Swaminathan et al. [3] from 2003, in that authors showed no differences of Sm values among different pediatric age groups. For the convenience of the audience of the European Journal of Pediatrics and especially for centers performing detailed TDI measurements, we want to add that our group has published normal $\mathrm{Sm}$ values with $Z$ scores in healthy children [2]. We suggest that a com-

Communicated by Jaan Toelen

Martin Koestenberger

Martin.Koestenberger@medunigraz.at; koestenbergerm@gmx.at

1 Division of Pediatric Cardiology, Department of Pediatrics, Medical University Graz, Auenbruggerplatz 30, 8036 Graz, Austria

2 Division of Pediatric Cardiology, Johns Hopkins University School of Medicine, Baltimore, MD, USA parison of the measured Sm data in children with EAT to available pediatric Sm normal values would have improved the statistical power of their analysis and therefore emphasizing the high value of a TDI investigation of the LV in children with EAT. We further want to strengthen the value of the recent data from Ge et al. [1] in contrast to the overaged findings from Swaminathan et al. [3]. We want to thank the authors for addressing the usefulness of TDI measurements as alternatives to the conventionally used LVEF. In our opinion, TDI parameters such as the Sm should be carefully investigated in children with congenital or acquired heart disease. We may add that even without a large experience, high-quality acquisition and analysis of the Sm can be easily performed. We hope that with more interesting studies like this from $\mathrm{Ge}$ et al. [1], this simple quantification of systolic LV function will become an easy available routine tool for all sonographers and physicians.

\section{References}

1. Ge HY, Li XM, Tang XJ, Zhang Y, Liu HJ, Li YH (2015) Optimal noninvasive assessment of initial left ventricular dysfunction in children with ectopic atrial tachycardia. Eur J Pediatr. doi:10.1007/ s00431-015-2500-1

2. Koestenberger M, Nagel B, Ravekes W, Avian A, Cvirn G, Rehak T, Gamillscheg A (2014) Reference values of the mitral annular peak systolic velocity (Sm) in 690 healthy pediatric patients, calculation of Z-score values, and comparison to the mitral annular plane systolic excursion (MAPSE). Echocardiography 31:11221130

3. Swaminathan S, Ferrer PL, Wolff GS, Gómez-Marín O, Rusconi PG (2003) Usefulness of tissue Doppler echocardiography for evaluating ventricular function in children without heart disease. Am J Cardiol 91:570-574 